\title{
Does availability of informal care within the household impact hospitalisation?
}

\author{
FRANCE M. WEAVER* \\ SSPH+ Assistant Professor, Department of Economics, University of Geneva, Geneva, Switzerland \\ BRYCE A. WEAVER \\ Department of Mathematics, Indiana University, Bloomington, IN, USA
}

\begin{abstract}
This study assesses the effect of having informal support available at home on inpatient care use in Switzerland. The main contributions are to consider the availability of care regardless of its source, measured by multipleadult living arrangements, and to examine this effect by type of inpatient care and source of potential support. A two-part model with region and time fixed effects is estimated to determine the impact of informal care availability on the likelihood of hospitalisation and length of stay, conditional on hospitalisation. The analysis is conducted on a sample of individuals aged $18+$ from four waves of the Swiss Household Panel survey (2004-2007). Overall, availability of informal care has no impact on the likelihood of hospitalisation but does significantly reduce length of stay by 1.9 days. Available support has no effect on the shortest stays (up to 10 days), but has a significant impact on acute care stays up to 30 days and longer stays. Additionally, the effect does not significantly vary whether the source of informal support is a spouse only, a spouse and other adults, or other adults only. These results indicate that social changes leading to an expansion in the proportion of one-person households may increase future inpatient care use.
\end{abstract}

Received 25 February 2013; revised 25 February 2013; accepted 4 March 2013; first published online 8 April 2013

\section{Introduction}

In most OECD countries, ageing of the population increases the number of persons in need of health care services. In Switzerland from 2009 to 2030, the proportion of persons aged 65 and over is projected to grow from $17 \%$ to $25 \%$ of the population and reach 2 million [Federal Statistical Office (FSO), 2010a]. Simultaneously, social changes modify care and living arrangements. Availability of informal care becomes less common because of increasing divorce rates, women labour force participation, reduced fertility rates, greater geographic

*Correspondence to: France M. Weaver, SSPH+ Assistant Professor, Department of Economics, University of Geneva, Bd du Pont d'Arve 40, 1211 Geneva 4, Switzerland. E-mail: france.weaver@unige.ch 
mobility and declining intergenerational co-residence. These demographic and social trends lead to an increasing number of one-person households. In Switzerland, the proportion of such households has increased from $20 \%$ to $36 \%$ from 1980 to 2005 and is projected to reach $41 \%$ by 2030 (FSO, 2010b). As a consequence, in the future, individuals may have smaller networks for the provision of informal care.

The economic literature on living arrangement decisions within families is motivated by the underlying assumption that living arrangements have implications on health care utilisation, mainly long-term care - formal in-home care and nursing home use (Stern, 1995; Börsch-Supan et al., 1996; Hoerger et al., 1996; Engers and Stern, 2002; Dostie and Léger, 2005; Pezzin et al., 2007; Byrne et al., 2009). These works argue that people who live alone and need health care may rely more on the formal health care system than individuals who reside with other adults and thus have informal care available to them - i.e. substitution between formal and informal care. Despite such motivation, the goal of these analyses is not to assess the relationship between living arrangements and health care use but to understand the determinants of living arrangements.

There are two bodies of literature interested in the effect of informal care on health care use: the studies focusing on living arrangements, as indicator of availability of support at home, and the ones considering actual provision of informal care, mainly by children. Both groups of works assess the effect of living and care arrangements of the elderly persons on their long-term care decisions; mostly nursing home use (e.g. Newman et al., 1990; Jette et al., 1995; Charles and Sevak, 2005; Kasper et al., 2010). Limited attention has been paid to the effect of informal care on acute care use, such as hospitalisation (Van Houtven and Norton, 2004, 2008; Bolin et al., 2008).

Empirically, living arrangements of the elderly persons have typically been measured by marital status, living alone or with others, and/or household size (e.g. Newman et al., 1990; Lui et al., 1994; Hays et al., 2003; Kasper et al., 2010). The early analyses on the effect of the actual provision of informal care on long-term care use were conducted in the United States in the 1980s and 1990s (e.g. Greene 1983; Noelker and Bass, 1989; Newman et al., 1990; Hanley et al., 1991; Jette et al., 1995). The more recent works concentrate only on informal care provided by children to their elderly parent (Lo Sasso and Johnson, 2002; Van Houtven and Norton, 2004, 2008; Bolin et al., 2008; Bonsang, 2009). These later works use hours of care provided by non-coresiding children as indicator of informal care. Over the last decade, the effect of available support from all sources on health care use has not received much attention, with the exception of Kasper et al. (2010) that consider the effect of living arrangements on nursing home use in the United States.

In Switzerland as in most western countries, the main caregivers are spouses or partners, followed by children who care mainly for unmarried individuals 
(Höpflinger and Hugentobler, 2005; Stuckelberger and Wanner, 2005). In 2007, $52 \%$ of the informal care recipients received help from a spouse or a partner and $44 \%$ from a child; whether or not they reside with their parent [(these proportions are not mutually exclusive (FSO, 2011)].

This study assesses the effect of multiple-adult living arrangement, as indicator of availability of informal care within a household, on hospitalisation. Its main contributions are to consider the entire adult population and all the potential sources of support within household, including spouses. A further contribution is the decomposition of this effect by source of potential support i.e. residing with a spouse only, with a spouse and other adults (mainly children), or with other adults only (no spouse).

This study focuses on hospitalisation because, in Switzerland, inpatient care represents the largest share of total health care expenditures. In 2007, inpatient care amounted to $41 \%$ of total health care expenditures, with $27 \%$ for acute care only, and $14 \%$ for non-acute inpatient care - long-term stays and rehabilitation stays. Length of stay is higher in Switzerland than in most other western countries, with over 7 days on average. In this context, this study also investigates the effect of availability of informal care on acute care stays - defined as stays up to 30 days - and longer non-acute stays.

\section{Background}

Considering whether an individual lives in shared household gives information on the availability of informal care within the household and the possibility of monitoring and observing a household member's health and behaviours. Economic studies interested in the role of family in the provision of care have focused mainly on shared living arrangements between children and their elderly parents (Stern, 1995; Börsch-Supan et al., 1996; Hoerger et al., 1996; Dostie and Léger, 2005; Pezzin et al., 2007; Byrne et al., 2009). These studies consider three living arrangements: living independently (with or without a spouse), cohabiting with children and living in a nursing home. They concentrate on developing theoretical models of family decision making and on discovering the determinants of cohabiting with children or being in a nursing home. No distinction is made between living with a spouse or alone, despite the fact that having a spouse indicates that informal support is available at home and living alone means that no support is available within the household. Here, the focus is on whether potential support is available within the household among individuals residing in the community.

As mentioned above, most empirical studies on living arrangements consider their impacts on nursing home use. They are mainly conducted in the United States and rely on data from the 1980s and 1990s. Gaugler et al. (2007) conduct a meta-analysis of the main determinants of nursing home entry and conclude that available support, measured by being married or living with others, reduces 
the risk of nursing home entry by $40-50 \%$. The effect of available support on hospitalisation has not received much attention (Miller and Weissert, 2000).

\subsection{Informal care and hospitalisation}

A small number of studies have analysed the effect of the actual provision of informal care on inpatient care use and results are contrasted (Van Houtven and Norton, 2004, 2008; Bolin et al., 2008). Bolin et al. (2008) estimate the effect of informal support provided by children and grandchildren on the use of diverse types of care, including hospitalisation, of single persons aged 50 and over in Europe. Using data from the 2004 Survey of Health, Ageing and Retirement in Europe (SHARE), they find that informal care increases the likelihood of hospitalisation. This effect is small but significant: a $10 \%$ raise in hours of informal care increases by 0.1 percentage point the probability of hospitalisation in a year. No significant effect of informal care is detected on length of stay, conditional on hospitalisation. Van Houtven and Norton (2004) rely on 1993 and 1995 US data to determine the effect of informal care provided by children to single individuals aged 70 and over. Informal care does not impact the likelihood of hospitalisation but does significantly reduce length of stay. A person receiving no informal care spends, on average, 7.0 days at the hospital, compared with 2.4 days for those receiving 20 hours of informal care. In another study, the same authors estimate the impact of informal care on Medicare expenditures (Van Houtven and Norton, 2008). The results are similar to those of their former paper: informal care does not impact the likelihood of having any Medicare-financed hospitalisation, but does reduce Medicare expenditures among hospitalised individuals. To summarise, one European study finds that informal care slightly increases the likelihood of hospitalisation, while two US studies conclude that informal care has no effect on the likelihood of hospitalisation but does significantly reduce length of stay.

The generalisation of existing results is limited for two main reasons. First, the recent studies on living arrangements, as measures of available support, concentrate on their effects on long-term care use. Second, the analyses on the actual hours of informal care focus on the supply by children to single individuals only, when the majority of the population is married or has a partner. No recent work on inpatient care has considered the effect of available support from all sources provided to the entire adult population, whether married or not.

Theoretically, most research on living arrangements and care decisions rely on one of two conceptual frameworks (explicitly or implicitly): the expanded Andersen behavioural model of health services use (Andersen, 1968, 1995), mainly used in gerontology and sociology, and the Becker framework of household decisions making (Becker, 1981), found in the economic literature. Both theories postulate that informal care - either its availability or actual provision - is an important determinant of the use of health care services. 
Holding other characteristics constants, living arrangements are determinants of hospitalisation if availability of informal care reduces or increases utilisation of such formal health care services. If having someone available for help at home reduces hospitalisation, then informal care substitutes for hospitalisation (negative relationship). For example, informal care may reduce the risk of adverse health outcomes by supervising the patient and consequently reducing the risk of hospitalisation. Informal support could also increase the productivity of inpatient care or offer post-hospitalisation help resulting in reduced length of stay (Bolin et al., 2008). Inversely, if availability of support increases hospitalisation, then informal care is a complements to such care (positive relationship). For example, a spouse or an adult child can initiate hospitalisation or encourage the patient to remain longer at the hospital (Van Houtven and Norton, 2008). Co-residing with an adult may also encourage the patient to remain independent as long as possible and thus to rely on the formal health care system when needed.

In economic terms, a sufficient condition for informal care to be a substitute to formal care is that the marginal benefit of hospitalisation, given availability of informal care, is negative (Van Houtven and Norton, 2004, 2008; Bolin et al., 2008). In that case, a person values an extra unit of inpatient care less than being at home if caregivers are available for help. On the other hand, such availability may complement hospitalisation if the marginal benefit of hospitalisation is positive; a person values an extra unit of inpatient care more than being at home because of the presence of informal caregivers.

Intuitively, a distinction seems necessary between the risk of hospitalisation and its duration. Based on the above discussion, the effect of availability of informal care on the likelihood of hospitalisation is difficult to anticipate as all arguments seem relevant. Once hospitalised, its effect on length of stay is anticipated to be negative because, in general, patients and his or her family value being home more than remaining at the hospital.

\subsection{Availability of informal care and type of hospitalisation}

The effect of availability of informal care may depend on the type of inpatient care. Short stays are usually related to acute care that mainly treats unanticipated health shocks with the goal of restoring good health through the provision of skilled and specialised health care services. Longer stays are often related either to post-acute care, such as rehabilitation, or long-term care that concerns chronic conditions or irreversible degradation in health (Norton, 2000). On one hand, availability of informal care may have a limited impact on short-term stays as help from a spouse or an adult child may not substitute well for acute care that requires mainly skilled support. On the other hand, availability of informal care may better substitute for longer non-acute hospital stays as informal care usually consists in support with activities of daily living (ADL) and instrumental activity of daily living. Existing research on the effect of 
informal care on hospitalisation has not considered the distinct nature of acute and non-acute inpatient care as they consider all self-reported hospitalisations regardless of length of stay (Van Houtven and Norton, 2004, 2008; Bolin et al., 2008). This study investigates whether availability of informal care has an impact on acute inpatient stays (up to 30 days) or whether the results are driven by longer non-acute stays.

\subsection{Sources of informal support}

The effect of availability of informal care on hospitalisation may depend on the relationship between the potential caregivers and the health care user. Numerous studies document that being married or co-residing with an adult reduces nursing home use (e.g. Gaugler et al., 2007; Weaver et al., 2009; Kasper et al., 2010). For example, Freedman (1996) documents that being married diminishes the likelihood of institutionalisation more than having a daughter. Van Houtven and Norton (2008) examine the effect of informal care from children on health care use according to marital status. Informal care provided by children does significantly reduce hospital length of stay among non-married elderly but does not among married elderly. As the model is estimated separately for married and non-married elderly, the effect of marital status is unknown. Most of the literature measures living arrangements by marital status or not living alone. Co-residence with adult children or other relatives has received limited attention, with the exception of Kasper et al. (2010) that consider the effect of diverse living arrangements on nursing home placement.

The differential effect of informal care by type of caregivers may be explained by different opportunity costs for spouses, adult children or other adults, distinct motivations or social justifications to provide help, or different preferences of the potential care recipient and provider. Thus, the effect of availability of informal support may vary according to who is available for help in the household: a spouse/partner, other adults (mainly children), or both.

\subsection{Hypotheses}

Conceptually, availability of informal care may increase or decrease the likelihood of hospitalisation. However, once hospitalised, availability of informal care is expected to decrease length of stay. Furthermore, such effect may vary by source of available support (spouse, other adults or both) and by type of hospitalisation (acute vs non-acute care). To summarise, this study tests four hypotheses:

1. Availability of informal care has an impact on the likelihood of hospitalisation, without being able to hypothesise the direction of the effect.

2. Availability of informal care reduces length of stay, conditional on hospitalisation.

3. Availability of informal care has no effect on acute care stays - up to 30 days. The effect is driven by long-term stays - over 30 days. 
4. The effect of availability of informal care differs by source of potential support: spouse only, spouse with other adults and other adults only.

\section{Empirical method}

As a large proportion of individuals have no hospitalisation in a given year, a two-part model is estimated (Duan et al., 1984). The first part is a logit model that predicts the likelihood of hospitalisation and the second part is ordinary least square model that predicts logged number of days spent at the hospital, conditional on hospitalisation. This dependent variable is logged to reduce the influence of outliers.

The four hypotheses are tested by considering the estimated coefficients of availability of informal care in each part of the model separately. The effect of availability of informal care on the likelihood of hospitalisation is an empirical question because, as mentioned above, the theory does not clearly tell whether there is an effect and its direction (Hypothesis 1). In contrast, the coefficient of availability of informal care on length of stay is hypothesised to be negative (Hypothesis 2). To test Hypothesis 3 of no effect of availability of informal care on acute care stays, the length of stay equation is estimated five times: stays up to 10,18 and 30 days capture acute care hospitalisations, and stays up to 60 and 100 days add non-acute inpatient care. The OECD defines acute inpatient care as hospital stays up to 18 days (OECD, 2011). This definition is fairly restrictive and is not commonly used empirically. Thus, we also consider the usual 30-day definition of acute care. The longer stays can be considered as non-acute or even long-term care. Significant effects are expected only in the equations including non-acute stays over 30 days. To test the last hypothesis, the indicator of availability of informal care is decomposed into three components: residing with a spouse or a partner only, residing with a spouse/partner and other adult(s) and residing with other adult(s) only (no spouse). The statistical test consists in determining whether the estimated coefficients are statistically the same (Hypothesis 4).

The two-part model is the following:

$$
\begin{aligned}
\operatorname{Pr}\left[\operatorname{hosp}_{i, h, t}=1\right] & =\frac{1}{1+e^{-\left(\alpha_{0}+\alpha_{1} \text { avail_informal }_{h, t}+\alpha_{2} X_{i, h, t}+v_{i, h, t}\right)}} \\
\ln \left[\operatorname{LOS}_{i, h, t} \mid\left(\operatorname{hosp}_{i, h, t}=1\right)\right] & =\beta_{0}+\beta_{1} \text { avail_informal }_{h, t}+\beta_{2} X_{i, h, t}+\varepsilon_{i, h, t}
\end{aligned}
$$

The subscripts and the variables are the same in the logit and log-linear specifications: $i, b$ and $t$ refer to the individual, his or her household, and the year of the survey. The error terms are $v_{i, h, t}$ and $\varepsilon_{i, h, t}$. The dependent variables, the key variable of interest, avail_informal ${ }_{h, t}$, and the list of control variables, $X_{i, h, t}$, are presented below (in Sections 3.1-3.3). 


\subsection{Dependent variables}

The dependent variables are a binary indicator of hospitalisation in the last 12 months for the logit model, $\operatorname{Pr}\left[\right.$ hosp $\left._{i, h, t}=1\right]$, and a continuous measure of the natural logged number of days spent at the hospital, conditional on being hospitalised, $\ln \left[\operatorname{LOS}_{i, h, t} \mid\left(\operatorname{hos}_{i, h, t}=1\right)\right]$. In that latter model, the estimated coefficients are semi-elasticities, i.e. a unit change in a right-hand side variable causes a percentage change in the dependent variable.

Both variables are drawn from the following question: 'Since (month, year) how many days have you spent in hospital or specialized clinic, not including spas or wellness cures?'. Hospitalisation is coded as 1 if this value is $\geq 1$ and 0 if it is zero. Length of stay is derived directly from the response.

\subsection{Availability of informal care}

The overall indicator of availability of informal care within the household, avail_informal $_{h, t}$, is a binary indicator taking value 1 if two adults or more reside together and value 0 if the household is composed of one adult. An adult is defined as a person aged 18 and over. She or he might be a spouse, a partner (for non-married couples), a parent, a child or an unrelated adult. The coefficients of interest are $\alpha_{1}$ and $\beta_{1}$.

When the indicator is decomposed into three binary variables, they take value 1 if the condition is fulfilled and 0 otherwise: (i) living with a spouse or partner only, (ii) living with a spouse/partner and other adult(s) who are mainly children and (iii) living with other adult(s) only (no spouse). In the specifications, the omitted category is living alone.

\subsection{Explanatory variables}

The vector of individual-level variables, $X_{i, h, t}$, adjusts for health status, sociodemographic characteristics, indicators of pressure to be or return home, regional fixed effects (i.e. canton) and year dummy variables for time fixed effects.

Health status is controlled for as thoroughly as the data allows using indicators of current health, limitations in everyday activities and a couple of health-related behaviours. Current health is assessed by self-reported health categorised into three groups: poor health, fair health and good health as the reference category. A dichotomous indicator captures suffering from a chronic condition and one indicator capture having regular pain due to headaches or back pains. The level of ADL limitations is measured by a scale ranging from 0 for no impediment to 10 for severe limitations. Three categories are created: severe limitations if the value on the scale is 7 and over, some limitations if it is between 5 and 6, and moderate or no limitation for values below 5 (reference category). There are also binary indicators of being physically active and being obese, defined as a body mass index of 30 and over.

The socio-demographic characteristics include interaction terms between gender and three age categories - 18-39, 40-64 and 65+- the omitted category 
being male aged 18-39. Other binary indicators are for whether the household resides in an urban or rural area, Swiss nationality and education level compulsory school only, professional education, and tertiary education as the reference category. Household income in 10,000 Swiss francs is controlled for using a continuous indicator. Health insurance is not controlled for because it is compulsory in Switzerland. All residents have a basic policy that provides fairly comprehensive coverage for acute inpatient care. Supplemental health insurance schemes are optional and some of them provide access to a private or semiprivate (two persons) room in hospitals as well as the free selection of the intervening doctors. Some may expect that such additional coverage may induce longer lengths of stay. In 2006, some $22 \%$ of insured individuals had this type of supplemental coverage [Federal Office of Private Insurance (FOPI), 2010]. No information on these health plans is available in the Swiss Household Panel. However, such coverage is highly related to income, which partly captures such unobserved health insurance effect (Schellhorn, 2001; Dormont et al., 2009).

Special attention is devoted to hospitalisations that are attributable to deliveries. Such hospitalisations are not caused by a need for health care to restore health. Thus, they differ fundamentally from the other causes of hospitalisation. An indicator of 'being a woman with a newborn' - i.e. a child less than 1-year old - allows controlling for childbirth over the last 12 months. The correlation between being a woman aged $18-39$ and having a newborn is 0.17 , and with having children between 1 and 5 years old, it is 0.38 . This latter is the largest correlation found between explanatory variables.

The last group of control variables includes indicators of pressure to remain at home or to return home in case of hospitalisation: having children under 18 and working. It is assumed that the younger the child is, the larger the pressure is to be home and avoid hospitalisation or to limit length of stay. This effect may vary by gender. In particular, mothers with young children have a strong incentive to limit hospitalisations. Interactions between gender and children age are created: women with child $<1$-year old (same variable as above), women with children between the age of 1 and 5, women with children 6 and over, men with children under 5, and men with children aged 6 and over. Additionally, the pressure to be at home is anticipated to be higher for individuals having jobs than those who are not working. Professional activity is captured by two binary variables of having a fulltime job or a part-time job, with the omitted group being individuals who do not work.

\subsection{Clustering and endogeneity}

Time trend is taken into account by using wave fixed effects. Because individuals are observed repeatedly over time, standard errors are adjusted for withinindividual clustering. Individual fixed effects cannot be controlled for because most individuals do not have any hospitalisation and most of those who were 
hospitalised had only one stay. Similarly household-fixed effect is not adjustable because it is rare to observe multiple hospitalisations within a given household over a four-year time span.

In Switzerland, there are noticeable differences in health care utilisation across cantons, e.g. in 2005, hospitalisation rates varied between $10.6 \%$ and $16.1 \%$ across cantons [Swiss Health Observatory (Obsan), 2010a, 2010b]. Such variation is explained, not only by differences in the demographic composition of the canton populations, with some cantons having older population than others, but also by cultural differences and various organisations of the health care markets. Switzerland has three main linguistic regions - German, French and Italian - with distinct traditions, cultural habits and political preferences that may influence health care utilisation. Furthermore, cantons are in charge of the planning of hospital beds, which results in differences in the provision of inpatient care, e.g. the number of acute care beds varies from 2.0 to 7.2 per 1000 inhabitants across cantons in 2005 [Obsan (Swiss Health Observatory), 2010a, 2010b]. Lastly, variation across cantons in the access to professional home care services is documented as well (Jaccard-Ruedin et al., 2006). As for hospital care, cantons are responsible for the delivery of formal home care services. If such care is correlated with both availability of informal care and hospitalisation, it could bias estimates. Empirically, unobserved heterogeneity in demand and supply across cantons is taken into account by adjusting for canton-fixed effects.

One methodological challenge is that availability of informal care may be endogenous to hospitalisation. In the three studies investigating the effect of informal care by children on use of inpatient care by single individuals, results are conflicting: using European data, Bolin et al. (2008) find that such support is exogenous to hospitalisation when Van Houtven and Norton $(2004,2008)$, using US data, document that it is endogenous. When considering multiple-adult living arrangements, some may argue that they are partly caused by unobserved health status and health care needs of one of the household members. In particular, adult children may decide to live with their parents or siblings to provide help to one of them. Such endogeneity may occur among individuals who face a permanent degradation in their health status. However, it is less likely when considering the overall adult population because inpatient care needs are unexpected, in most cases. Additionally, in Switzerland as in some other European countries, adult children tend to live with their parents until their mid-20s or older, for educational and economic reasons. Among individuals with children, one-third of those aged 50-64 and $8 \%$ of those $65+$ still live with their children in 2000 (Fux et al., 2006). Another source of endogeneity may arise if being married, the main component of the measure of availability of informal care, is associated with unobserved good health status. A large body of literature documents that marriage or cohabiting with a partner has a protective effect on health (Lillard and Panis, 1996; Wood et al., 2007). If some unobserved dimensions of good health are positively correlated with being married, the 
implication is that our estimates suffer from a downward bias, and thus provide a conservative estimate (Wooldridge, 2000).

Statistically, unobserved factors that determine both availability of informal care and hospitalisation may cause the indicator of availability of informal care to be correlated with the error term, resulting in biased estimates. To limit the risk of such bias, health status is controlled for as thoroughly as the data set allows. Three sensitivity checks are performed. First, the models are re-estimated without health indicators to observe how sensitive the estimates on availability of informal care are to observed health status. Second, the models are re-estimated using lagged availability of informal care - at wave $t-1$ - on the sample of individuals who were not hospitalised at $t-1$. This strategy reduces the simultaneity between living arrangement decisions and the use of inpatient care, and it relies on a sample of relatively healthy individuals as they did not have any hospitalisation in the preceding year. Third, the inverse of the main model is estimated by using our indicator of available support within the household as the outcome and being hospitalised as a right-hand side variable. We run the model twice, once with being hospitalised currently and once with being hospitalised at the former wave $(t-1)$. Such reverse model will provide some insight on the potential risk of reverse causality.

\section{Data}

The Swiss Household Panel is a multidisciplinary survey with a nationally representative longitudinal sample. The sample is stratified by region and represents the non-institutionalised population in Switzerland. It consists of two independent samples, drawn in 1999 and in 2004, respectively. The sampling frame was the Swiss phone directory, which covers an estimated $95 \%$ of all households in Switzerland. Within each household, all individuals aged 14 or older are interviewed by phone each year (www.swisspanel.ch).

The analysis is conducted on four waves of the data: 2004, 2005, 2006 and 2007. These waves are chosen because the number of days spent in a hospital or clinic has been asked since 2004. The analysis is restricted to adults, i.e. individuals who are 18 and older. Filtering missing data results in a sample of 22,789 person-wave observations. The majority of the missing data is on household income with $10.3 \%$ of non-responses. The likelihood of hospitalisation is estimated on the complete sample of observations $(n=22,789)$ and length of stay on the sample of hospitalised individuals with length of stay shorter or equal to 100 days $(n=3254)$. This restriction reduces the effect of 20 outliers that have lengths of stay between 101 and 180 days.

\section{Results}

\subsection{Overview of the sample}

Participants are 47.2 years old, on average, with the youngest being 18 and the oldest 95 years old. The proportion of women reaches $55 \%$. Among hospitalised 
individuals, the average age is slightly higher (50.3 years old), the youngest being 18 and the oldest 94, and the proportion of women is $56 \%$. Table 1 reveals that $14 \%$ of the observations had a hospitalisation in the 12 months preceding the interview. Among hospitalised individuals, the average length of stay is 7.2 days. The average proportion and length of stay are comparable with the ones found in the Swiss registry on hospitalisations that include all hospitalisation in 2007 (FSO, 2010a, 2010b).

Proportions of individuals with informal support available at home are similar in the complete sample $(79 \%)$ and among hospitalised individuals $(81 \%)$, as are the proportions of women, Swiss nationals and levels of education. As anticipated, hospitalised individuals have worse health status than the entire sample, e.g. people with poor health represent $2 \%$ of the overall sample, compared with $6 \%$ among hospitalised persons. Similarly, the proportion of men and women aged 65 and over is larger among hospitalised persons $(12 \%$ and $13 \%$ ) than in the overall surveyed population $(7 \%$ and $9 \%)$. Inversely, indicators of pressure to remain or return home have lower proportions among hospitalised individuals than in the overall sample; the largest difference is observed for being employed full-time, with $32 \%$ and $39 \%$, respectively.

As mentioned above, in the complete sample, the proportion of multiple-adult households reaches $81 \%$ and one-adult household represents $19 \%$. Among multiple-adult households, $67.6 \%$ co-reside with a spouse only, $16.5 \%$ live with a spouse and other adults (a child, sibling or other adult) and $15.9 \%$ live with other adults but without a spouse.

\subsection{Effect of availability of informal care}

In the second part of the model, the choice of logged length of stay is confirmed by a PE test (McKinnon et al., 1983). Predicted length of stay is corrected to take into account this nonlinear transformation of the dependent variable. The exponentiated predicted length of stay for each observation is multiplied by the smearing factor, defined as the mean exponentiated predicted errors. As there is some heteroscedasticity by gender, distinct smearing factors are estimated for males and females (Manning, 1998). The predicted effect of availability of informal care is determined as the mean difference between the predicted length of stay (corrected by the smearing factor) with and without availability of informal care for each observation.

Having informal care available at home is not significantly related to the likelihood of hospitalisation in Switzerland (Table 2, column 1). In the logit model, the coefficient on availability of informal care is small and not significant. Thus, the first hypothesis is rejected: statistically, individuals living with other adults and those living alone have the same probability of being hospitalised.

However, availability of informal care does significantly impact length of stay, at $1 \%$ (Table 2 , column 2 ). The second hypothesis is confirmed: individuals 
Table 1. Descriptive statistics of variables entering into the empirical model

\begin{tabular}{|c|c|c|c|c|}
\hline & \multicolumn{2}{|c|}{ Entire sample $(n=22,789)$} & \multicolumn{2}{|c|}{ Hospitalised individuals $(n=3254)$} \\
\hline & Mean & Standard deviation & Mean & Standard deviation \\
\hline \multicolumn{5}{|l|}{ Dependent variables } \\
\hline Any hospitalisation & 0.14 & 0.35 & 1.0 & 0.0 \\
\hline No hospitalisation $^{\text {a }}$ & 0.86 & 0.35 & - & - \\
\hline Length of stay ${ }^{\mathrm{b}}$ & $\begin{array}{c}1.14 \\
{[0 ; 180]^{\mathrm{b}}}\end{array}$ & 6.33 & $\begin{array}{c}7.2 \\
{[1 ; 100]^{b}}\end{array}$ & 11.3 \\
\hline \multicolumn{5}{|l|}{ Variable of interest } \\
\hline Availability of informal care & 0.81 & 0.40 & 0.79 & 0.40 \\
\hline No informal care available ${ }^{a}$ & 0.19 & 0.40 & 0.21 & 0.40 \\
\hline \multicolumn{5}{|l|}{ Health indicators } \\
\hline Good health ${ }^{\mathrm{a}}$ & 0.85 & 0.35 & 0.71 & 0.45 \\
\hline Fair health & 0.13 & 0.33 & 0.23 & 0.42 \\
\hline Poor health & 0.02 & 0.14 & 0.06 & 0.24 \\
\hline No regular pain ${ }^{a}$ & 0.82 & 0.38 & 0.75 & 0.43 \\
\hline Regular pain & 0.18 & 0.38 & 0.25 & 0.43 \\
\hline No chronic conditions ${ }^{\mathrm{a}}$ & 0.65 & 0.48 & 0.52 & 0.50 \\
\hline Chronic condition & 0.35 & 0.48 & 0.48 & 0.50 \\
\hline No or few limitations ${ }^{\mathrm{a}}$ & 0.81 & 0.39 & 0.66 & 0.47 \\
\hline Some limitations & 0.10 & 0.30 & 0.17 & 0.38 \\
\hline Severe limitations & 0.09 & 0.28 & 0.17 & 0.37 \\
\hline Not physically active ${ }^{a}$ & 0.62 & 0.48 & 0.64 & 0.48 \\
\hline Physically active & 0.36 & 0.48 & 0.36 & 0.48 \\
\hline Not obese $^{a}$ & 0.92 & 0.27 & 0.88 & 0.32 \\
\hline Obese & 0.08 & 0.27 & 0.12 & 0.32 \\
\hline \multicolumn{5}{|l|}{ Socio-demographic characteristics } \\
\hline Woman 18-39 & 0.18 & 0.39 & 0.19 & 0.39 \\
\hline Woman 40-64 & 0.28 & 0.45 & 0.24 & 0.42 \\
\hline Woman $65+$ & 0.09 & 0.29 & 0.13 & 0.34 \\
\hline Man $18-39^{a}$ & 0.16 & 0.36 & 0.12 & 0.33 \\
\hline Man 40-64 & 0.22 & 0.42 & 0.20 & 0.40 \\
\hline Man $65+$ & 0.07 & 0.26 & 0.12 & 0.32 \\
\hline Gross income in $10 \mathrm{k}^{\mathrm{b}}$ & $\begin{array}{c}12.41 \\
{[0.5 ; 512]^{\mathrm{b}}}\end{array}$ & 11.49 & $\begin{array}{c}11.74 \\
{[0.68 ; 300]^{\mathrm{b}}}\end{array}$ & 9.90 \\
\hline Not rural area ${ }^{a}$ & 0.85 & 0.36 & 0.84 & 0.36 \\
\hline Rural area & 0.15 & 0.36 & 0.16 & 0.36 \\
\hline Not Swiss ${ }^{a}$ & 0.09 & 0.29 & 0.09 & 0.29 \\
\hline Swiss nationality & 0.91 & 0.29 & 0.91 & 0.29 \\
\hline Tertiary education $^{\mathrm{a}}$ & 0.43 & 0.49 & 0.39 & 0.49 \\
\hline Professional education & 0.42 & 0.49 & 0.45 & 0.50 \\
\hline Compulsory school only & 0.15 & 0.36 & 0.16 & 0.37 \\
\hline \multicolumn{5}{|l|}{ Pressure to be or return home } \\
\hline Woman without a child $<18^{a}$ & 0.81 & 0.40 & 0.80 & 0.40 \\
\hline Woman with newborn & 0.01 & 0.09 & 0.05 & 0.22 \\
\hline Woman with child $1-5$ & 0.05 & 0.23 & 0.06 & 0.24 \\
\hline Woman with child $6+$ & 0.13 & 0.34 & 0.09 & 0.29 \\
\hline Man without a child $<18^{\text {a }}$ & 0.84 & 0.37 & 0.87 & 0.34 \\
\hline Man with child $0-5$ & 0.05 & 0.22 & 0.04 & 0.20 \\
\hline
\end{tabular}


Table 1. (Continued)

\begin{tabular}{lccccc}
\hline \hline & \multicolumn{2}{c}{ Entire sample $(n=22,789)$} & & \multicolumn{2}{l}{ Hospitalised individuals $(n=3254)$} \\
\cline { 2 - 3 } & Mean & Standard deviation & & Mean & Standard deviation \\
\hline \multirow{2}{*}{ Man with child 6+ } & 0.11 & 0.31 & & 0.09 & 0.29 \\
No job & 0.37 & 0.48 & & 0.47 & 0.50 \\
Fulltime job & 0.39 & 0.49 & & 0.32 & 0.46 \\
Part-time job & 0.24 & 0.42 & & 0.21 & 0.41 \\
\hline \hline
\end{tabular}

Notes: ${ }^{a}$ Reference category of categorical variables in regressions.

${ }^{\mathrm{b}}$ Continuous variables with minimum and maximum values in brackets.

living in a multiple-adult household have, on average, a hospital stay that is 1.9 days shorter than individual living without other adult (Table 3, bottom row). Specifically, individuals who live without other adult are predicted to stay in the hospital for 8.5 days on average while individuals who reside with other adults are predicted to stay for 6.6 nights. This effect is fairly large as availability of informal care at home reduces length of stay by about $26 \%$ on average (Table 2).

In both regressions, the control variables have the expected sign (Table 2). Overall, the main determinants of the likelihood of hospitalisation and length of stay are the health-related variables and age. The factors having the largest effects on the likelihood of hospitalisation are being in poor health and having given birth in the last 12 months. In the other model, length of stay is largely influenced by being in poor health, having severe ADL limitations and being an elderly man or woman. For example, being a woman aged 65 and over results in length of stays that are, on average, 55\% longer than for males aged 18-39 (reference category).

With the exception of age and gender, the socio-demographic variables have limited effects; the largest being the effect of having a professional training on the likelihood of hospitalisation (significant at $5 \%$ ). The indicators of pressure to return home - i.e. having young children or a job - do not influence much the likelihood of hospitalisation, with the obvious exception of having a newborn (as most women deliver at the hospital). Similarly, having given birth in the last 12 months has a large effect on length of stay. The other indicators of pressure to return home play a limited role. The largest and most significant effect is observed for being employed fulltime, which reduces length of stay by $19.0 \%$ on average compared with not working.

Significant differences are observed in the likelihood of hospitalisation across cantons. Canton-fixed effects are jointly significant $[F(25,22734)=3.01$, Prob $>F=0.00]$. However, once hospitalised, length of stay does not significantly differ at $5 \%$ across cantons $[F(25,3199)=1.44$, Prob $>F=0.07]$. Thus, unobserved differences in supply and demand across cantons impact the probability of being hospitalised but play a lesser role on duration of hospitalisation. 
Table 2. Two-part model: effect of availability of informal care on the probability of hospitalisation and length of stay

\begin{tabular}{|c|c|c|}
\hline & $\begin{array}{c}\text { Probability of } \\
\text { hospitalisation }(n=22,789)\end{array}$ & $\begin{array}{l}\text { Ln (length of stay) conditional } \\
\text { on hospitalisation }(n=3254)\end{array}$ \\
\hline Availability of informal care & $0.01(0.06)$ & $-0.26(0.06)^{* * *}$ \\
\hline \multicolumn{3}{|l|}{ Health indicators } \\
\hline Fair health ${ }^{\mathrm{a}}$ & $0.60(0.06)^{* * *}$ & $0.17(0.05)^{* * *}$ \\
\hline Poor health ${ }^{\mathrm{a}}$ & $1.26(0.11)^{* * *}$ & $0.49(0.10)^{* * *}$ \\
\hline Regular pain ${ }^{\mathrm{b}}$ & $0.05(0.06)$ & $-0.01(0.05)$ \\
\hline Chronic condition $^{c}$ & $0.28(0.05)^{* * *}$ & $0.02(0.04)$ \\
\hline Some limitations ${ }^{\mathrm{d}}$ & $0.53(0.07) * * *$ & $0.30(0.06)^{* * *}$ \\
\hline Severe limitations ${ }^{\mathrm{d}}$ & $0.64(0.07) * *$ & $0.50(0.06)^{* * *}$ \\
\hline Physically active $\mathrm{e}^{\mathrm{e}}$ & $0.09(0.04)^{* *}$ & $0.05(0.04)$ \\
\hline Obese $^{f}$ & $0.26(0.07) * *$ & $-0.002(0.06)$ \\
\hline \multicolumn{3}{|l|}{ Socio-demographic characteristics } \\
\hline Woman $18-39^{\mathrm{g}}$ & $-0.19(0.09) * *$ & $0.06(0.08)$ \\
\hline Woman 40-64 & $-0.21(0.09)^{* *}$ & $0.16(0.07) * *$ \\
\hline Woman $65+^{\mathrm{g}}$ & $0.21(0.10) * *$ & $0.55(0.09) * *$ \\
\hline Man $40-64^{\mathrm{g}}$ & $-0.02(0.08)$ & $0.31(0.07)^{* * *}$ \\
\hline Man $65+^{\mathrm{g}}$ & $0.49(0.10)^{* * *}$ & $0.45(0.09) * * *$ \\
\hline Gross household income (10k) & $0.002(0.00) *$ & $-0.000(0.003)$ \\
\hline Rural area & $0.05(0.07)$ & $0.11(0.06)^{*}$ \\
\hline Swiss nationality & $0.001(0.08)$ & $-0.10(0.07)$ \\
\hline Professional education & $0.11(0.05)^{* *}$ & $0.01(0.04)$ \\
\hline Compulsory school only & $-0.01(0.07)$ & $-0.08(0.06)$ \\
\hline \multicolumn{3}{|l|}{ Pressure to be or return home } \\
\hline Women with newborn ${ }^{\mathrm{h}}$ & $4.50(0.28)^{* * *}$ & $0.69(0.08) * * *$ \\
\hline Woman with child $1-5^{\mathrm{h}}$ & $0.51(0.10) * * *$ & $0.12(0.09)$ \\
\hline Woman with child $6+{ }^{\mathrm{h}}$ & $-0.15(0.08)^{* *}$ & $-0.08(0.07)$ \\
\hline Man with child $0-5^{\mathrm{i}}$ & $-0.07(0.12)$ & $-0.01(0.10)$ \\
\hline Man with child $6+^{\mathrm{i}}$ & $-0.004(0.09)$ & $0.04(0.07)$ \\
\hline Fulltime job & $-0.10(0.07)$ & $-0.19(0.06)^{* * *}$ \\
\hline Part-time job & $-0.10(0.07)$ & $-0.08(0.05)$ \\
\hline Intercept & $-2.20(0.13)^{* * *}$ & $1.22(0.12)^{* * *}$ \\
\hline
\end{tabular}

Notes: Standard errors are reported in parentheses. Time and canton fixed effects are not reported here and are available on request.

The reference categories are as follows:

${ }^{\text {a}}$ Being in good health.

${ }^{\mathrm{b}}$ No regular pain.

${ }^{\mathrm{c}}$ No chronic illness.

${ }^{\mathrm{d}}$ No limitation.

${ }^{\mathrm{e}}$ Not physically active.

${ }^{\mathrm{f}}$ Not obese.

${ }^{\mathrm{g}}$ Man 18-39.

${ }^{\text {h}}$ Women without child $<18$.

${ }^{\mathrm{i}}$ Men without child. All the other reference categories work in the same way.

*** Significant at $1 \%$, * significant at $5 \%$, "significant at $10 \%$. 
Table 3. Effect of availability of informal care by type of care

\begin{tabular}{ll}
\hline \hline & Predicted effect on length of stay \\
\hline Acute care only & \\
LOS $\leq 10(n=2730)$ & 0.10 \\
LOS $\leq 18(n=2943)$ & $-0.36^{*}$ \\
LOS $\leq 30(n=3131)$ & $-0.64 * *$ \\
Acute and non-acute care & $-1.34^{* * *}$ \\
LOS $\leq 60(n=3230)$ & $-1.92^{* * *}$ \\
LOS $\leq 100(n=3254)$ & \\
\hline \hline
\end{tabular}

LOS $=$ length of stay.

Notes: $* *$ Significant at $1 \%, *$ significant at $5 \%$, significant at $10 \%$.

\subsection{Effect of availability of informal care by type of hospitalisation}

As expected, the shortest stays - i.e. up to 10 days - are not impacted by availability of informal care (Table 3). The coefficient is small and not significant. For acute care stays up to 18 days (OECD definition), availability of informal care is not significant at $5 \%$ but is at $10 \%$, with a decrease in length of stay of 0.36 day. When considering all acute care stays up to 30 days, availability of informal care significantly reduces length of stay by 0.64 day (at 5\%). Statistically, this effect is significantly smaller than the effect on longer non-acute. When considering non-acute stays, availability of informal care becomes a highly significant predictor of length of stay. Up to 60-day hospitalisations, availability of informal significantly reduces length of stay by 1.3 days. For all stays up to 100 days (main results), the effect reaches 1.9 days on average. These results emphasise that, despite what was hypothesised, availability of informal care has an impact on acute care stays. The effect is driven by stays over 18 days.

\subsection{Effect by source of potential support}

Whether the source of support comes from a spouse or other adults has no differential effect on both the likelihood of hospitalisation and length of stay. Thus, the fourth hypothesis is rejected. More specifically, no type of co-residence has an impact on the likelihood of hospitalisation but they all have a significant impact on length of stay (Table 4). Having a spouse and other adults at home reduces length of stay by 2.0 days, compared with 1.9 days for residing with a spouse only or with other adult only. The three effects are statistically the same as indicated by the joint $F$-test $[F(2,2483)=0.04$, Prob $>F=0.96]$. To summarise, all the sources of potential support significantly reduce length of stay, and the magnitudes of these effects are the same (full models in Appendix). 
Table 4. Effect of availability of informal care by source of potential support

\begin{tabular}{lcc}
\hline \hline & \multicolumn{2}{c}{ Predicted effect on } \\
\cline { 2 - 3 } & Probability of hospitalisation & Length of stay \\
\hline Partner only & 0.03 & $-1.94^{* * * *}$ \\
Partner \& other adult(s) & -0.10 & $-2.03^{* * *}$ \\
Other adult(s) only & -0.01 & $-1.86^{* * *}$ \\
\hline \hline
\end{tabular}

Notes: LOS model: cumulative $F$-test of equal coefficients: $F(2,2483)=0.04$.

Prob $>F=0.96$.

$n=22,789$ and $n=3254$, respectively.

$* *$ Significant at $1 \%$.

\subsection{Robustness checks}

Running the models with and without health status characteristics does not statistically impact the estimates on availability of informal care (at 5\%). Without any health indicator, availability of informal care significantly reduces length of stay by 2.1 days, compared with 1.9 days with such controls. Second, availability of informal care at the previous wave does not impact the likelihood of hospitalisation among individuals who did not have a hospitalisation at former wave $(n=14,278)$. It does significantly reduce length of stay by 2.1 days among this sample of healthy individuals $(n=1432)$, compared with 1.9 days for the complete sample of hospitalised individuals. Lastly, running the inverse model, any current or lagged hospitalisation does not significantly relate to the likelihood of having informal care available at home ( $p$-values of no effect: 0.89 and 0.58 , respectively). These three sensitivity tests - for unobserved health status and the simultaneity between living arrangement and hospitalisation suggest that the results are robust and the risk of endogeneity is limited.

\section{Discussion}

This paper is one of the few that investigates the link between availability of informal care and inpatient care use. It documents that informal care available at home does not impact the likelihood of hospitalisation but does significantly reduce length of stay by 1.9 days. Stated differently, individuals living alone have a length of stay that is nearly two days longer, on average, than those co-residing with other adults. Holding other things constant, living arrangements influence inpatient care use and thus may have an impact on the financial burden of public payers and private households. In Switzerland, inpatient care is financed primarily by public subsidies, social health insurance and out-of-pocket.

The cost implications of the findings are non-negligible as average daily inpatient care costs reach CHF 1380 in 2007 [own estimation based on total 
hospital costs and number of hospital days in 2007 (Morger and Rossel, 2009)]. If, as forecasted, the proportion of one-person households increases, it will increase both public and private spending for health care. Analysing the effect of living arrangements on health care expenditures and public spending would be particularly useful to policy makers.

The findings are consistent with Van Houtven and Norton (2004, 2008), who identify no effect on the likelihood of hospitalisation but an effect on length of stay. Bolin et al. (2008) have the reverse results: informal care impacts the risk of hospitalisation but not its duration. These studies consider the actual provision of informal care by adult children or grandchildren to single older persons. The present analysis adopts a broader perspective by focusing on the entire adult population and multiple-adult living arrangements as indicators for availability of support from all sources in the household.

This study also adds to the literature by documenting that the source of availability of care (spouses, other adults or both) does not have a differential effect on hospitalisation. It also confirms that availability of informal care has an impact on acute care stays and is not solely driven by longer hospital stays. Currently in Switzerland, an effort is being made to reduce hospitalisation for non-acute care by encouraging alternative forms of care, such as ambulatory care or specific types of institutionalisation. In the future, if length of stay diminishes, the effect of multiple-adult household may be of smaller magnitude but may still be significant.

This study suffers from some caveats. First, the sample includes individuals living in the community only, who are healthier than the overall population. Using data that follows individuals into institutions is needed to address this potential selection bias. Once more waves of the SHARE data are available, they may be able to fill this gap. Second, the distinction between types of hospitalisation (acute and non-acute care) is based on an empirical cut-off at 30 days; it serves as a first exploration of the issue. Third, the causal relationship between availability of informal care and hospitalisation is not fully addressed. Although there are controls for potential cofounders, the findings may partly reflect some underlying factors, such as support from individuals outside the household. The sensitivity checks indicate that the endogeneity of availability of informal care may not be an issue here; finding similar to the other European study (Bolin et al., 2008). Nonetheless, further research should investigate whether living arrangements are endogenous, even if this should be less of an issue for inpatient care than long-term care use (formal in-home care and nursing home). Fourth, availability of informal care may suffer from some measurement error because co-residing adults may be unable or unwilling to provide care. Yet, such phenomenon is likely to be random, conditional on covariates, and thus may not bias estimates. Using actual hours of informal care provided by spouses and other co-residing adults would be of interest. Such measure may also suffer from measurement errors because it is empirically challenging to disentangle help 
because of care needs from help attributable to the share of duties when cohabiting, e.g. cooking or cleaning. For example, Giovannetti and Wolff (2010) and Van den Berg and Spauwen (2006) raise the difficulties in assessing the actual use of informal care and the need for further developments in survey design on this issue. Overall, a better understanding of how family members share the burden of caring is also needed. Availability of informal care from noncoresiding relatives, in particular children, may also impact hospitalisation. In Switzerland, $1.8 \%$ of women and $0.6 \%$ of men are caregivers to relatives living outside their household (Schön-Bühlmann, 2008). Another phenomenon is growing in Switzerland and in some other western countries: the development of communal living arrangements among unrelated adults. These structures are different from assisted living facilities because they do not provide any formal care. Attention should be paid to the specific impact of these diverse forms of informal support on health care utilisation.

In the context of ageing and social changes, the development of effective policies to meet health care needs requires understanding the effects of sociodemographic factors on health care utilisation. In Switzerland, policy makers have started to pay some attention to the provision of informal care as an alternative to more costly forms of care. Similarly, encouraging cohabitation, either among family members or non-family members, is a policy option to explore. Currently, the health care financing system is based primarily on individuals needing formal care and rarely recognises informal support (Stuckelberger and Wanner, 2005). Public financing could partly re-orientate its focus by providing incentives to multiple-adult living arrangements in order to promote not only family co-residence, but also shared living arrangements among unrelated adults. Encouraging family or other co-residents to provide care will not solve the problem of expanding health care expenditures but may mitigate its increase.

\section{Acknowledgement}

The authors thank Prof. Dean Lillard for valuable advice and the two reviewers of this paper for suggestions. The authors also thank the participants to the 5th International Conference of Panel Data Users in Switzerland and the Research Seminar in Gerontology at University of Geneva for useful comments.

The analyses were conducted in SAS 9.1.3 and Stata 11.1.

\section{References}

Andersen, R. M. (1968), Behavioral Model of Families' Use of Health Services, Research Series No. 25. Chicago, IL: Center for Health Administration Studies, University of Chicago.

Andersen, R. M. (1995), 'Revisiting the behavioral model and access to medical care: does it matter?', Journal of Health and Social Behaviour, 36(1): 1-10. 
Becker, G. (1981), Treatise on the Family, Cambridge MA: Harvard University Press.

Bolin, K., B. Lindgren and P. Lundborg (2008), 'Informal and formal care among single-living elderly in Europe', Health Economics, 17(3): 393-409.

Bonsang, E. (2009), 'Does informal care from children to their elderly parents substitute for formal care in Europe?', Journal of Health Economics, 28(1): 143-154.

Börsch-Supan, A., D. McFadden and R. Schnabel (1996), 'Living Arrangements: Health and Wealth Effects', in D. Wise (ed.), Advances in the Economics of Aging, Chicago: University of Chicago Press, 193-212.

Byrne, D., M. S. Goeree, B. Hiedermann and S. Stern (2009), 'Formal home health care, informal care, and family decision making', International Economic Review, 50(4): 1205-1242.

Charles, K. K. and P. Sevak (2005), 'Can family caregiving substitute for nursing home care?', Journal of Health Economics, 24(6): 1174-1190.

Dormont, B., P. Y. Goeffard and K. Lamiraud (2009), 'The influence of supplemental health insurance on switching behavior: evidence from Swiss data', Health Economics, 18(11): 1339-1356.

Dostie, B. and P. T. Leger (2005), 'The living arrangement dynamics of sick, elderly individuals', The Journal of Human Resources, 40: 989-1014.

Duan, N., W. G. Manning, C. N. Morris and J. P. Newhouse (1984), 'Choosing between the sample-selection and multi-part model', Journal of Business and Economic Statistics, 2(3): 283-289.

Engers, M. and S. Stern (2002), 'Long-term care and family bargaining', International Economic Review, 43: 1-44.

Federal Office of Private Insurance (FOPI) (2010), 'Facts and Figures', http://www.finma.ch/ archiv/bpv/e/themen/00503/00607/index.html?lang=en [April 2010].

Federal Statistical Office (FSO) (2010a), Population résidante permanente par sexe et âge selon le scénario A-00-2005/09 de 2009 à 2050, http://www.bfs.admin.ch/bfs/portal/fr/ index/themen/01/03/blank/key/ind_erw.html [March 2010].

FSO (2010b), Ménages privés en Suisse par taille du ménage selon le scénario AM-00-2005 de 2005 à 2030, http://www.bfs.admin.ch/bfs/portal/fr/index/themen/01/03/blank/key_ hhsz.html [March 2010].

FSO (2011), 'Swiss Health Survey, 2007', http://www.bfs.admin.ch/bfs/portal/en/index/ themen/14/22/publ.html? [November 2011].

Freedman, V. A. (1996), 'Family structure and the risk of nursing home admission', Journal of Gerontology: Social Sciences, 51B: S61-S69.

Fux, B., C. Sauvain-Dugerdil, H. Stutz, S. Strub, A. Leuba, C. Tritten and J. Krummenacher (Hrsg.) (2006), Pflegen, betreuen und bezablen. Familien in späteren Lebensphasen, Bern: Bundesamt für Sozialversicherung.

Gaugler, J. E., S. Duval, K. A. Anderson and R. L. Kane (2007), 'Predicting nursing home admission in the US: a meta-analysis', BMC Geriatrics, 7-13: 1-14.

Giovannetti, E. R. and J. L. Wolff (2010), 'Cross-survey differences in national estimates of numbers of caregivers of disabled older adults', Milbank Quarterly, 88(3): 310-349.

Greene, V. L. (1983), 'Substitution between formally and informally provided care for the impaired elderly in the community', Medical Care, 21(6): 609-619.

Hanley, R. J., J. M. Wiener and K. M. Harris (1991), 'Will paid home care erode informal support?', Journal of Health Politics, Policy and Law, 16(3): 507-521.

Hays, J. C., C. F. Pieper and J. L. Purser (2003), 'Competing risk of household expansion or institutionalization in later life', Journal of Gerontology Social Sciences, 58: S11-S20. 
Hoerger, T. J., A. Picone and F. A. Sloan (1996), 'Public subsidies, private provision of care and living arrangement of the elderly', The Review of Economics and Statistics, 78(3): 428-440.

Höpflinger, F. and V. Hugentobler (2005), Familiale, ambulante und stationäre Pflege im Alter. Perspektiven für die Schweiz, Bern: Verlag Hans Huber.

Jaccard-Ruedin, H., A. Weber, S. Pellegrini and C. Jeanrenaud (2006), Comparaison intercantonale du recours aux soins de longue durée en Suisse, Document de travail 17. Neuchâtel: Obsan.

Jette, A. M., S. Tennstedt and S. Crawford (1995), 'How does formal and informal community care affect nursing home use', Journal of Gerontology Social Sciences, 50(1): S4-S12.

Kasper, J. D., L. E. Pezzin and J. Bradford Rice (2010), 'Stability and changes in living arrangements: relationship to nursing home admission and timing of placement', Journal of Gerontology Social Sciences, 65B(6): 783-791.

Lillard, L. A. and C. W. A. Panis (1996), 'Marital status and mortality: the role of health', Demography, 33(3): 313-327.

Lo Sasso, A. T. and R. W. Johnson (2002), 'Does informal care from adult children reduce nursing home admissions for the elderly?', Inquiry, 39: 279-297.

Lui, K., T. McBride and T. Coughlin (1994), 'Risk of entering nursing homes for long versus short stays', Medical Care, 32: 315-327.

MacKinnon, J., H. White and R. Davidson (1983), 'Tests for model specification in the presence of alternative hypotheses: some further results', Journal of Econometrics, 21: 53-70.

Manning, W. G. (1998), 'The logged dependent variable, heteroscedasticity, and the retransformation problem', Journal of Health Economics, 17: 283-295.

Miller, E. A. and W. G. Weissert (2000), 'Predicting elderly people's risk for nursing home placement, hospitalization, functional impairment, and mortality: a synthesis', Medical Care Research and Review, 57(3): 259-297.

Morger, M. and R. Rossel (2009), Coût et financement du système de santé. Résultats détaillés 2007 et évolution récente, Neuchâtel: Federal Statistical Office.

Newman, S. J., R. Struyk, P. Wright and M. Rice (1990), 'Overwhelming odds: caregiving and the risk of institutionalization', Journal of Gerontology Social Sciences, 45: S173-S183.

Noelker, L. S. and D. M. Bass (1989), 'Home care for elderly persons: linkages between formal and informal caregivers', Journal of Gerontology Social Sciences, 44(2): S63-S70.

Norton, E. C. (2000), 'Long-term care', in Culyer A. J. and Newhouse, J. P. (eds), Handbook of Health economics, New York, NY: Elsevier Science B. V.

OECD (2005), Long-Term Care for Older People, Paris: OECD editions.

OECD (2011), Statistical portal, Glossary of statistical terms, http://stats.oecd.org/glossary/ detail.asp? ID $=5$ [November 2010].

Pezzin, L. E., R. A. Pollak and B. S. Schone (2007), 'Efficiency in family bargaining: living arrangement and caregiving decisions of adult children and disabled elderly parents', CESifo Economic Studies, 53(1): 69-96.

Schellhorn, M. (2001), 'The effect of variable health insurance deductible on the demand for physician visits', Health Economics, 10(5): 441-456.

Schön-Bühlmann, J. (2008), Le travail bénévole en Suisse, Neuchâtel: Federal Statistical Office.

Swiss Health Observatory (Obsan) (2010a), Taux d'hospitalisation dans les hôpitaux de soins généraux et cliniques spécialisées, sauf les cliniques de psychiatrie, de réadaptation et de gériatrie, pour 1000 habitants, http://www.obsandaten.ch/indikatoren/6_1_1/2005/f/ 611.pdf [March 2010]. 
Obsan (2010b), Densité des lits d'hospitalisation par 1000 habitants dans les hôpitaux de soins généraux et cliniques spécialisées, sauf les cliniques de psychiatrie, de réadaptation et de gériatrie, pour 1000 habitants, http://www.obsandaten.ch/indikatoren/5_2_1/ 2005/f/521.pdf [March 2010].

Stern, S. (1995), 'Estimating family long-term care decisions in the presence of endogenous child characteristics', Journal of Human Resources, 30: 551-580.

Stuckelberger, A. and P. Wanner (2005), Services for supporting family carers of elderly people in Europe: characteristics, coverage and usage. EUROFAMCARE. National background report for Switzerland, Supported by the European Union, contract QLK6CT-2002-02647. Geneva: University of Geneva.

Van den Berg, B. and P. Spauwen (2006), 'Measuring of informal care: an empirical study into the valid measurement of time spent on informal care giving', Health Economics, 15: 447-460.

Van Houtven, C. H. and E. C. Norton (2004), 'Informal care and health care use of older adults', Journal of Health Economics, 23(6): 1159-1180.

Van Houtven, C. H. and E. C. Norton (2008), 'Informal care and Medicare expenditures: testing for heterogeneous treatment effects', Journal of Health Economics, 27(1): 134-156.

Weaver, F., S. C. Stearns, E. C. Norton and W. Spector (2009), 'Proximity to death and participation in the long-term care market', Health Economics, 18(8): 867-883.

Wood, R. G., B. Goesling and S. Avellar (2007), The effects of marriage on health: a synthesis of recent research evidence, Prepared for the Department of Health and Human Services, contract number 233-02-0096, Mathematica Policy Research Inc, http://aspe.hhs.gov/ hsp/of/marriageonhealth.

Wooldridge, Y. H. (2000), Econometric Analysis of Cross Section and Panel Data, 1st edition, Cambridge, MA: MIT Press.

Appendix. Two-part model with decomposition of source of care

\begin{tabular}{|c|c|c|}
\hline & $\begin{array}{c}\text { Probability of } \\
\text { hospitalisation }(n=22,789)\end{array}$ & $\begin{array}{l}\text { Ln (length of stay) conditional } \\
\text { on hospitalisation }(n=3254)\end{array}$ \\
\hline \multicolumn{3}{|l|}{ Availability of informal care } \\
\hline Partner only & $0.03(0.06)$ & $-0.26(0.06) * * *$ \\
\hline Partner and other adult(s) & $-0.10(0.08)$ & $-0.27(0.08) * * *$ \\
\hline Other adult(s) only & $-0.01(0.08)$ & $-0.25(0.09) * * *$ \\
\hline \multicolumn{3}{|l|}{ Health indicators } \\
\hline Fair health ${ }^{\mathrm{a}}$ & $0.60(0.06)^{* * *}$ & $0.18(0.05) * * *$ \\
\hline Poor health ${ }^{\mathrm{a}}$ & $1.26(0.11)^{* * *}$ & $0.49(0.10) * * *$ \\
\hline Regular pain ${ }^{\mathrm{b}}$ & $0.05(0.05)$ & $-0.01(0.05)$ \\
\hline Chronic illness ${ }^{\mathrm{c}}$ & $0.28(0.04) * * *$ & $0.02(0.04)$ \\
\hline Some limitations ${ }^{\mathrm{d}}$ & $0.53(0.06) * * *$ & $0.29(0.06) * * *$ \\
\hline Severe limitations ${ }^{\mathrm{d}}$ & $0.64(0.07) * * *$ & $0.50(0.06) * *$ \\
\hline Physically active $\mathrm{e}^{\mathrm{e}}$ & $0.09(0.04) * *$ & $-0.05(0.04)$ \\
\hline Obese $^{\mathrm{f}}$ & $0.26(0.07) * * *$ & $-0.001(0.06)$ \\
\hline \multicolumn{3}{|c|}{ Socio-demographic characteristics } \\
\hline Woman 18-39g & $-0.19(0.09) * *$ & $0.06(0.08)$ \\
\hline Woman $40-64^{\mathrm{g}}$ & $0.20(0.09) * *$ & $0.16(0.08)^{* *}$ \\
\hline Woman $65+^{\mathrm{g}}$ & $0.19(0.10) *$ & $0.55(0.10)^{* * *}$ \\
\hline
\end{tabular}


Appendix. (Continued)

\begin{tabular}{|c|c|c|}
\hline & $\begin{array}{c}\text { Probability of } \\
\text { hospitalisation }(n=22,789)\end{array}$ & $\begin{array}{l}\text { Ln (length of stay) conditional } \\
\text { on hospitalisation }(n=3254)\end{array}$ \\
\hline Man $40-64^{\mathrm{g}}$ & $-0.01(0.08)$ & $0.31(0.07) * * *$ \\
\hline $\operatorname{Man} 65+^{\mathrm{g}}$ & $0.47(0.10)^{* * *}$ & $0.45(0.10)^{* * *}$ \\
\hline Gross household income (10k) & $0.003(0.002) *$ & $-0.000(0.003)$ \\
\hline Rural area & $0.05(0.06)$ & $0.10(0.06)^{*}$ \\
\hline Swiss nationality & $0.002(0.07)$ & $-0.10(0.07)$ \\
\hline Professional education & $0.11(0.05)^{* *}$ & $0.01(0.04)$ \\
\hline Compulsory school only & $0.001(0.06)$ & $-0.08(0.07)$ \\
\hline \multicolumn{3}{|l|}{ Pressure to be or return home } \\
\hline Women with newborn ${ }^{\mathrm{h}}$ & $4.47(0.26) * * *$ & $0.70(0.08) * * *$ \\
\hline Woman with child $1-5^{\text {h }}$ & $0.48(0.10)^{* * *}$ & $0.11(0.09)$ \\
\hline Woman with child $6+^{\mathrm{h}}$ & $-0.15(0.08)^{* *}$ & $-0.08(0.07)$ \\
\hline Man with child $0-5^{\mathrm{i}}$ & $-0.10(0.11)$ & $-0.01(0.10)$ \\
\hline Man with child $6+^{i}$ & $-0.000(0.08)$ & $0.03(0.07)$ \\
\hline Fulltime job & $-0.11(0.06)^{*}$ & $-0.19(0.06) * * *$ \\
\hline Part-time job & $-0.10(0.06)$ & $-0.08(0.06)$ \\
\hline Intercept & $-2.22(0.13) * * *$ & $1.23(0.12)^{* * *}$ \\
\hline
\end{tabular}

Notes: Standard errors are reported in parentheses. Time and canton fixed effects are not reported here and are available on request.

The reference categories are as follows:

${ }^{\mathrm{a}}$ Being in good health.

${ }^{\mathrm{b}}$ No regular pain.

${ }^{\mathrm{c}}$ No chronic illness.

${ }^{\mathrm{d}}$ No limitation.

${ }^{\mathrm{e}}$ Not physically active.

${ }^{\mathrm{f}}$ Not obese.

${ }^{\mathrm{g}}$ Man 18-39.

${ }^{\text {h}}$ Women without child $<18$.

${ }^{\mathrm{i}}$ Men without child. All the other reference categories work in the same way.

$* * *$ Significant at $1 \%, *$ significant at $5 \%$, "significant at $10 \%$. 